\title{
Endovascular Aneurysm Repair without Procedural Sedation
}

As many trials have demonstrated, endovascular aneurysm repair (EVAR) is an effective method to repair abdominal aortic aneurysms (AAAs). Although AAAs had previously been treated via open surgical repair, EVAR is associated with improved 30-day outcomes, similar long-term outcomes, and dramatically shorter recovery times. ${ }^{[1,2]}$ EVARs have traditionally been performed under general anesthesia in order to minimize patients' movements during the operation and optimize the precision of graft deployment. Within the last two decades, a number of studies have demonstrated that monitored anesthesia care in EVAR produces similar success and complication rates but lower hospital-stay time compared to general anesthesia. ${ }^{[3-6]}$

We intend to present a case of a percutaneous EVAR with local anesthesia only and without procedural sedation. Our patient is a 91-year-old male with a past medical history significant for AAA, Grade II diastolic heart failure, paroxysmal atrial fibrillation (only on aspirin given a history of gastrointestinal bleeding), chronic obstructive pulmonary disease, essential hypertension, prediabetes, and chronic cholecystitis status post recent placement of a cholecystostomy tube. The patient had also been recently treated for community-acquired pneumonia with cefpodoxime.

He presented to the emergency department with severe abdominal pain and was found to have an enlarging infrarenal AAA, measuring approximately $6.5 \mathrm{~cm}$ [Figure 1]. Given the patient's age and multiple comorbidities, he was deemed a poor candidate for open surgical repair, EVAR under general anesthesia, and EVAR with procedural sedation. We typically use intravenous versed and fentanyl for our percutaneous EVARs. However, given his multiple comorbidities and recent illnesses, we attempted to avoid using any sedative medications in this patient.

Generous subcutaneous injection of $1 \%$ lidocaine solution was performed at the entry under ultrasound guidance over the anterior surface of the common femoral arteries [Figure 2]. Bilateral arteriotomies were preclosed using two Perclose ProGlide $^{\circledR}$ (Abbott, Abbott Park, IL, USA). A 16 Fr GORE $^{\circledR}$ Dry Seal sheath (W. L. Gore and Associates, Inc. Flagstaff, AZ, USA) was placed in the left common femoral artery after serial fascial dilation, and a $12 \mathrm{Fr}$ sheath was placed in the right common femoral artery. The main body GORE EXCLUDER ${ }^{\circledR}$ Endoprosthesis (W. L. Gore and Associates, Inc.) was advanced via the left $16 \mathrm{Fr}$ sheath and deployed under fluoroscopic guidance. The GORE EXCLUDER (W. L. Gore and Associates, Inc.) contralateral limb was advanced into position via the $12 \mathrm{Fr}$ sheath and deployed under fluoroscopic guidance, followed by the GORE EXCLUDER ipsilateral limb (W. L. Gore and Associates, Inc.) in similar fashion via the $16 \mathrm{Fr}$ sheath [Figure 3]. Post deployed aortogram was performed.
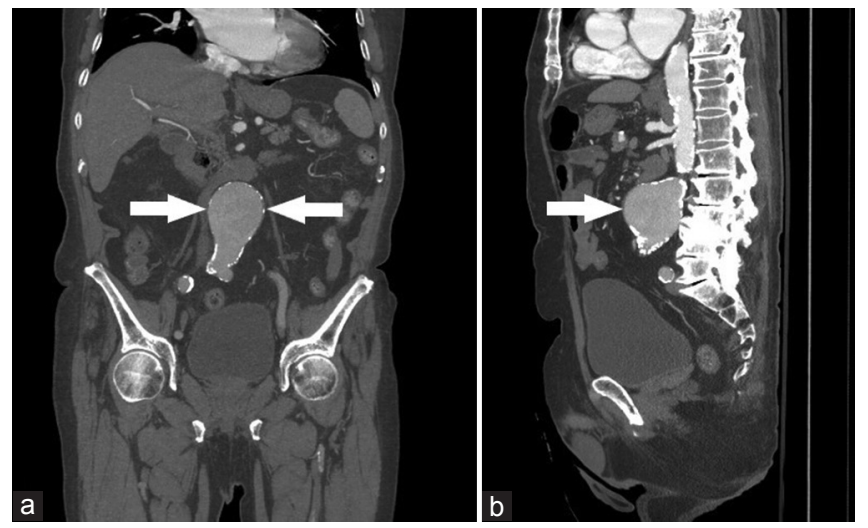

Figure 1: A 91-year-old male with abdominal aortic aneurysm. Coronal (a) and sagittal (b) computed tomography images demonstrating the infrarenal aortic fusiform aneurysm

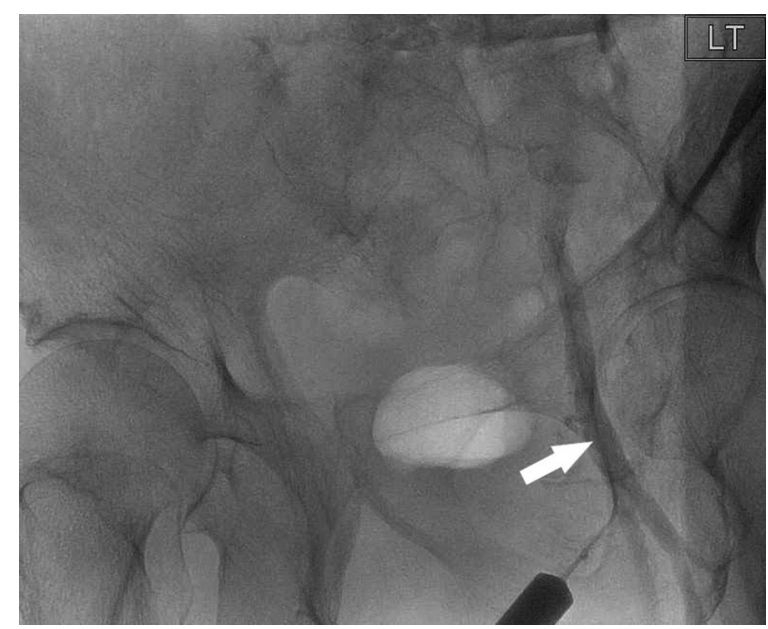

Figure 2: Percutaneous access of the bilateral common femoral arteries was obtained

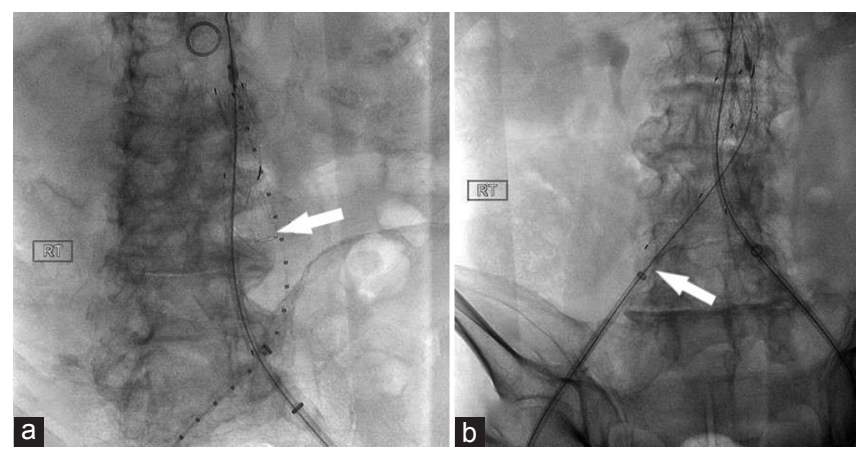

Figure 3: The main body of the endograft is deployed (a). The arrow is pointing toward the contralateral gate, which is cannulated and used to extend the contralateral limb (b) 


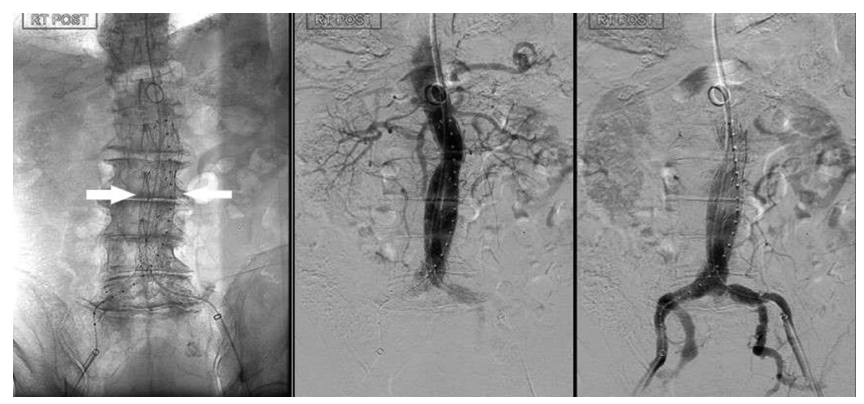

Figure 4: Final aortogram demonstrates the successful endovascular aneurysm repair. No endoleak is visualized

Evidence of endoleak was observed, and repeated molding of the proximal aortic graft and the overlapping segments was performed. Repeat aortography was performed demonstrating improved proximal and distal seal [Figure 4]. At the end of the case, all catheters and wires were removed. Throughout the case, a condom catheter was used to avoid the use of a Foley catheter. Immediate hemostasis was obtained in both groins using standard preclose techniques. The estimated blood loss was $<10 \mathrm{cc}$.

There were no postoperative complications, and the patient's abdominal pain resolved. The patient was able to ambulate, urinate, and resume his diet. His renal function remained stable with adequate urine output. He was discharged the following day in stable condition and had close postoperative follow-up at 2 weeks, 3 months, 6 months, 12 months, and 18 months. The patient continued to remain asymptomatic from his EVAR without need for further interventions.

Percutaneous EVAR without procedural sedation is not suitable for every patient given variations in patient pain tolerance and the complexity unique to every case. However, this case serves as a reminder that performing an EVAR without procedural sedation can be considered when age or comorbidities obviate the possibility of EVAR with general anesthesia or procedural sedation.

\section{Declaration of patient consent}

The authors certify that they have obtained all appropriate patient consent forms. In the form the patient(s) has/have given his/her/their consent for his/her/their images and other clinical information to be reported in the journal. The patients understand that their names and initials will not be published and due efforts will be made to conceal their identity, but anonymity cannot be guaranteed.

Financial support and sponsorship

Nil.

\section{Conflicts of interest}

There are no conflicts of interest.
Eric Mastrolonardo, Harout Dermendjian', John Do², Geogy Vatakencherry ${ }^{1}$

Medical Student, Sidney Kimmel Medical College, Thomas Jefferson University, Philadelphia, PA, ${ }^{1}$ Department of Radiology, Kaiser Permanente, Los Angeles, ${ }^{2}$ Department of Radiology, University of California, San Diego, CA, USA

Address for correspondence:
Mr. Eric Mastrolonardo,
Sidney Kimmel Medical College, Thomas Jefferson University,
Philadelphia, PA, USA.
E-mail: evm004@jefferson.edu
Received: 08-10-2019
Revised: 24-10-2019
Accepted: 22-11-2019
Published Online: 18-12-2019

\section{Bibliography}

1. IMPROVE Trial Investigators, Powell JT, Sweeting MJ, Thompson MM, Ashleigh R, Bell R, et al. Endovascular or open repair strategy for ruptured abdominal aortic aneurysm: 30 day outcomes from IMPROVE randomised trial. BMJ 2014;348:f7661.

2. Lederle FA, Freischlag JA, Kyriakides TC, Matsumura JS, Padberg FT Jr., Kohler TR, et al. Long-term comparison of endovascular and open repair of abdominal aortic aneurysm. N Engl J Med 2012;367:1988-97.

3. Franz RW, Nardy VJ, Burkdoll D. Endovascular repair of a large ruptured abdominal aortic aneurysm using monitored anesthesia care and local anesthesia. Int J Angiol 2014;23:121-4.

4. Geisbüsch P, Katzen BT, Machado R, Benenati JF, Pena C, Tsoukas AI. Local anaesthesia for endovascular repair of infrarenal aortic aneurysms. Eur J Vasc Endovasc Surg 2011;42:467-73.

5. Kothandan H, Haw Chieh GL, Khan SA, Karthekeyan RB, Sharad SS. Anesthetic considerations for endovascular abdominal aortic aneurysm repair. Ann Card Anaesth 2016;19:132-41.

6. Verhoeven EL, Cinà CS, Tielliu IF, Zeebregts CJ, Prins TR, Eindhoven GB, et al. Local anesthesia for endovascular abdominal aortic aneurysm repair. J Vasc Surg 2005;42:402-9.

This is an open access journal, and articles are distributed under the terms of the Creative Commons Attribution-NonCommercial-ShareAlike 4.0 License, which allows others to remix, tweak, and build upon the work non-commercially, as long as appropriate credit is given and the new creations are licensed under the identical terms.

\begin{tabular}{|l|l|}
\hline \multicolumn{2}{|c|}{ Access this article online } \\
\hline Quick Response Code: & Website: \\
& www.arabjir.com \\
\cline { 2 - 3 } & DOI: \\
\hline
\end{tabular}

How to cite this article: Mastrolonardo E, Dermendjian H, Do J, Vatakencherry $\mathrm{G}$. Endovascular aneurysm repair without procedural sedation. Arab J Intervent Radiol 2020;4:51-2.

Received: 08-10-2019, Revised: 24-10-2019, Accepted: 22-11-2019, Published Online: 18-12-2019.

(C) 2019 The Arab Journal of Interventional Radiology | Published by Wolters Kluwer - Medknow 